\title{
Las tensiones entre \\ lo global y lo local \\ en Lumpérica, de \\ Diamela Eltit
}

Ullla Szaszak

Recebido em: 4 de fevereiro de 2018

Aceito em: 18 de setembro de 2018
Professora de Letras pela Universidad

de Buenos Aires. Atualmente, é

mestranda no Programa de Pós-

-graduação em Estudos Literários

Latino-americanos na Universidad Tres de Febrero (UNTREF).

Contato: ulli_szo@hotmail.com 
PALABRAS CLAVES:

Global; Local; Identidad

nacional; Post-estructuralismo.
Lumpérica, de la escritora chilena Diamela Eltit (1983), pone en tensión las relaciones entre lo local y lo global al menos en dos dimensiones. En primer lugar, en el plano temático y político, en el que se juega el problema de la identidad (nacional), del cual participan los contextos slobales (económico-capitalistas) y los locales (la dictadura de Pinochet). Éstos delinean ciertas formas de existencia socioeconómicas de la (pos)modernidad que tendrían incidencia sobre las formas de construcción de una identidad local, "chilena" paradójicamente a partir de la priorización de aquellas identidades no canónicas en relación a la nacionalidad: los excluidos y los marginados. Y en sesundo lugar, la díada slobal-local se juega también en el plano teórico y estético, a partir de las elecciones implícitas y las afirmaciones metapoéticas de orden explícito que asdcribena corrientes estéticas y teóricas postestructuralistas que permiten no sólo un ocultamiento o disimulo del aspecto contextual, sino también una apropiación estética, a partir de ese entre-lugar latinoamericano (Santiago, 1978).

KEYWORDS: Local

Global, National identity;

Poststructuralism.
Lumpérica, by the Chilean writer Diamela Eltit (1983), reveals numerous tensions between the local and the slobal at least in two dimensions. In the first place, in regards to the thematic and political aspect, the problem of the (national) identity emerges, which involves the global (economic-capitalist) and local contexts (the Pinochet dictatorship). These delineate certain forms of socioeconomic existence of (pos)modernity that would have an impact on the forms of construction of a local "Chilean" identity, paradoxically based on the prioritization of those non-canonical identities in relation to nationality: the excluded and the marginalized. And secondly, the slobal-local dyad also takes place on the theoretical and aesthetic level, from the implicit choices and metapoetic affirmations of explicit order that ascribe to aesthetic and theoretical poststructuralist currents that allow not only a concealment or dissimulation of the contextual aspect, but also an aesthetic appropriation, from that Latin American "inter-place" (Santiago, 1978). 
En Lumpérica, de la escritora chilena Diamela Eltit (1983), las tensiones entre lo global y lo local están problematizadas en dos niveles. El primero es visible, temático y ligado a la ponderación de los entramados económicos de la globalización y el capitalismo (como una matriz impuesta, foránea en su gestación) y a su relación con lo local. Es decir, a las formas de existencia socioeconómicas de la (pos)modernidad, que tendrían cierta incidencia sobre las formas de construcción de una identidad local, paradójicamente a partir de la priorización de aquellas identidades no canónicas en relación a la nacionalidad, es decir, de los excluidos y los marginados. El segundo nivel adscribe estas tensiones de lo global-local a una concepción teórico-estética que la novela despliega y desde la cual se piensa, aunque implícitamente. Estas elecciones se relacionan con cierta filiación con las corrientes teóricas y estéticas del post-estructuralismo (Reber, 2005), a partir de una elección estética que es un gesto fundante y que más que un acto de discurso es un performativo (que hace gestos, guiños hacia ese carácter descentrado y fragmentario, propio de dichas corrientes). Pero además de esa dimensión estética y teórica subyacente, aparecen también ciertas reflexiones explícitas, metapoéticas, respecto de la literatura, por ejemplo en el apartado "Para la formulación de una imagen en literatura" ${ }^{-}$; que indagan en aquél "entrelugar", en términos de Silviano Santiago, de la producción latinoamericana que les permite intervenir en discusiones mundiales.

En principio, Lumpérica se publica en Chile en 1983, durante la dictadura militar encabezada por Augusto Pinochet, lo cual inserta a la obra

1 Este es el nombre que lleva el capítulo Cuatro de Lumpérica (1983). 
en función de ciertas tensiones contextuales que resultarían centrales para la consideración de la obra, aunque no sean explícitas en ella. A propósito de esto, Eltit señala en una entrevista:

El primer libro yo lo publiqué con una Oficina de Censura. Había una oficina burocrática, digamos, y todo libro que uno quisiera publicar tenía que ir a esa oficina y el Ministerio del Interior daba permiso o no para publicarlo. Había en ese tiempo una censura explícita, y la verdad es que tú podías publicar sin pasar por esa oficina pero, en ese caso, los libros no podían ir a librerías porque cuando se ponía un libro en librería tenía que tener el certificado del Ministerio del Interior diciendo que había sido aprobado (Solorza, 2016).

Este clima sociopolítico, que evidentemente tiene una influencia (material) sobre la concepción de la obra en términos de la selección de "lo narrable", rodea el texto como un fantasma, sin terminar de surgir del todo, pero que, a partir de esas restricciones contextuales, impone ciertos regímenes específicos de ocultamiento y visibilización en los cuales no dejan de participar esas tensiones entre lo global y lo local. Veremos que lo global, tanto en su veta estética, como en su veta socioeconómica, aparece como estrategia de ocultamiento en un caso, y de visibilización en el otro. Esto es, si se oculta la realidad política chilena, dictatorial, se visibiliza a la figura social que aparece despolitizada, a la que se le niega, de algún modo, el carácter de ciudadano: el lumpen. Lo local chileno aparece cifrado en lo local-marginal, el borde, lo cual, además de una denuncia político-social, implica un corrimiento de los "centros" de la postulación de una Identidad 
chilena. Como veremos más adelante, el marginal se vuelve ciudadano a partir de un elemento "global", externo.

\section{NOMINACIÓN SUPLEMENTARIA}

En el orden temático, toda la acción de Lumpérica se sitúa en la plaza pública de Santiago de Chile (referencia que aparece a veces - y de forma elusiva - como "Santiago" y que en los poemas se exhibe con el topónimo completo). Allí acuden un conjunto de los denominados "pálidos", desarrapados o lúmpenes: los seres innombrados e invisibilizados por la sociedad, quienes son bañados por la luz de un cartel publicitario, a quien llaman "El luminoso". Éste inscribe sobre sus cuerpos nuevos nombres cada noche y estos nombres, al bañarlos con la nueva inscripción (de consumo) los vuelve visibles, y por tanto, ciudadanos:

Porque el frío de esta plaza es el tiempo que se ha marcado para suponerse un nombre propio, donado por el letrero que se encenderá y apagará, rítmico y ritual, en el proceso que en definitiva les dará la vida: su identificación ciudadana (Eltit, 1983, p.7).

Estas escenas en las que la protagonista recibe el nombre de L. Iluminada se describen como si fueran rituales: son performances en que el cuerpo humano sirve como soporte que es transformado a partir del "goce" y "la crueldad” (Bortignon, 2011, p.57). De hecho, según Alberto López Martín en Lumpérica "la acción marginal privilegia el movimiento y el cambio sistémico, la performance, sobre el estatismo de un posicionamiento físico o ideológico concreto" (2016, p.22). De este modo se evidencia 
que la operación identitaria de la inscripción económica y política (cívica) no presupone la pasividad de los excluidos, sino que son los cuerpos en movimiento los que habilitan el pasaje nominal: el acto por el que son nombrados y vueltos sujetos políticos. Entonces, a nivel tematico, la primera tensión que se produce entre lo global y lo local es la paradoja de que el elemento que produzca aquella "identificación ciudadana”, más que un operador local, chileno y propio, se relacione con un cartel publicitario que, en términos de aquella estructura del capitalismo global (más allá del origen del producto publicitado en sí), responde a algo foráneo: una matriz que les ha sido impuesta a los países latinoamericanos (y todos aquellos que históricamente han sido reducidos a "periferias"). En ese sentido, opera una crítica del sistema económico como único agente de subjetivación nacional para los desclasados, codificada en la metáfora de la luz: sólo aquellos que están iluminados, visibles, pueden adquirir el estatuto de ciudadano. Según Martina Bortignon, los pordioseros "se venden a la plusvalía simbólica de la luz de un aviso comercial" (2011, p.56). Por lo tanto, ponen en evidencia aquel "proyecto biopolítico neoliberal" (2011, p.69). En este sentido es interesante el enfoque de José Antonio Paniagua García, quien señala que la escritura de Diamela Eltit "deviene estética encaminada a la descolonización del poder y el saber, para efectuar un debate acerca del pensamiento de la modernidad y su lógica colonial” (2014, p.80).

A pesar de que este acto de nominación suplementaria es producido por un recurso del mercado capitalista, neoliberal, que coloniza los cuerpos; paradójicamente permite hacer entrar a los pálidos en regímenes de subjetivación social y de visibilidad al manifestar dicha identificación 
ciudadana. Y en ese sentido se trata de una forma en que se subvierte - o, más bien problematiza - la colonización del mercado en una reterritorialización. Sin embargo, la adquisición de nombres, en lugar de evidenciar esa visibilización de los sujetos a partir de la figura de ciudadano, de aquel que se encuentra por dentro de un contrato social, por el contrario, produce la reivindicación de la dimensión biológica de los cuerpos - y por lo tanto, de su igualación en tanto cuerpos deseantes, finitos, vivos. Aparece el erotismo público: "Pero los pálidos siguen en el centro frotándose contra el cemento, rodando bajo los bancos de madera, frágiles de vestimentas pese al frío, gimiendo siempre" (Eltit, 1983, p.11). Allí, se invierten (y deconstruyen) las relaciones de poder (el panóptico) que organizaban el espacio público y el espacio privado (Barrientos, 2017, p.24); y de hecho se rompe la dicotomía: los desarrapados sexualizan el espacio público - la plaza -, y en ese sentido refuncionalizan ese espacio.

Ahora bien, ese proceso de nominación que realiza El Luminoso, en lugar de pregonar cierta "singularidad" de los individuos, los homogeneiza. Se trata de una estrategia de disolución momentánea de las castas sociales: "allí mismo muestran sus cuerpos que no plantean diferencias entre unos y otros: el aviso luminoso los encubre de distintas tonalidades, los encubre y los condiciona" (Eltit, 1983, p.8). Cualquier cuerpo en esa luz es igualado a los otros. En todo caso, se concibe la experiencia como una "pérdida" del nombre propio, lo que se pierde es la "costra personal" en el caso de L. Iluminada para "renacer lampiña acompañada por ellos" (Eltit, 1983, p.8). Y ese renacimiento tiene cierto tinte mesiánico en términos de una posibilidad revolucionaria. También se enfatiza la dimensión pre lingüística, 
pre-lógica: "con sonidos guturales llenan el espacio en una alfabetización virgen que altera las normas de la experiencia y así de vencedores a vencidos se convierten" (Eltit, 1983, p.10). Se testean, por otra parte, los límites corporales, la experiencia de la finitud: L. Iluminada que estrella su cabeza contra un árbol y contra el cemento para revelar la sangre que mana de su herida, y la herida misma como símbolo mismo de esa igualación biológica que deviene política.

\section{CORRIENTES ESTÉTICAS}

En términos estéticos, la elección de entroncarse implícitamente con corrientes teóricas posestructuralistas(y la producción literaria asociada a ellas) parece un gesto de deslocalización y de importación extranjera que es funcional a la operación de ocultamiento o disimulo de las cuestiones sociales y políticas que aparecen en Lumpérica. Estas formas de importación de teoría francesa y norteamericana (posestructuralista) aparece en la vertiente de la narración fragmentaria, dislocada, inorgánica, en que no se pueden reconstruir formas de la progresión narrativa sino que los episodios se construyen como micro-escenas fílmicas. De hecho, el lector descubre a posteriori que se encuentra frente a un discurso cinematográfico porque luego de estas descripciones aparecen otros fragmentos más bien evaluativos de lo anterior titulados: "Comentarios a la primera escena", "Indicaciones para la primera escena", "Errores de la primera toma" (Los subrayados son propios) (Cómo debería verse y cómo se ve efectivamente la escena). Es decir, las unidades de descomposición del discurso cinematográfico tanto en relación a la acción (las escenas) como a la técnica que interviene, también 
como un procedimiento compositivo (las tomas). De este modo, no es sólo la fragmentariedad del discurso, su no-progresión narrativa lo que imprime a Lumpérica rasgos de texto rupturista, posestructuralista, sino también la complejidad de sus efectos de genericidad (Adam, 2004), que la hace participar tanto del discurso cinematográfico (bajo el formato de escenas) en el que interviene también, subsumido, el género interrogatorio policial - como del discurso lírico: una gran zona del texto está compuesta por poemas. Es decir que este entramado de efectos de genericidad (y no de géneros cerrados y orgánicos) tienden hacia el estallido y la dispersión. De este modo, en este nivel del procedimiento estético, Lumpérica parece estar muy tensionada en función de teorías y literaturas importadas, globales. Cabe preguntarse, entonces, ¿En qué medida Lumpérica funciona como una apropiación de moldes teórico - literarios extranjeros, en relación a las "ideas fuera de lugar" de Schwartz, quien explicaba cómo en Brasil, un país esclavista, se pregonaba la democracia, aunque bajo una lógica nueva?

Para Silviano Santiago, el "entre-lugar" del discurso latinoamericano consiste en que América latina se posiciona el marco de la cultura mundial a partir de "un movimiento que activa y destructivamente desvía la norma, un movimiento que resignifica los elementos preestablecidos e inmutables que los europeos exportaban al nuevo mundo.” (1978, p.65). De este modo, la escritura debe afirmarse como "escritura sobre otra escritura", "una especie de traducción global, de pastiche, de parodia, de digresión y no como una traducción literal. (1978, p.71)" (los subrayados son propios) y que en tanto la segunda obra incorpora, muchas veces, una crítica de la anterior: "se impone con la violencia desmitificadora de las planchas anatómicas 
que dejan al desnudo la arquitectura del cuerpo humano" (1978, p.70). La paradoja de Lumpérica - o su mecanismo de subversión de la norma particular - parecería estar en aquello que en función de un contexto sociopolítico es preciso ocultar: las alusiones directas (y críticas) al estado de facto, al terrorismo de estado, y por tanto, a la esfera política en específico, porque hay una institución de control - la censura - que incide no sólo en las posibilidades de publicación del texto, sino en la potencial criminalización del autor como disidente político.

Ahora bien, este tipo de adopción de una poética post-estructuralista, fragmentaria, contribuye al disumulo - bajo esta la fachada de esta opacidad del significante - de aquello que aparece como una fuerte impronta política (velada) del texto: la deconstrucción de la identidad (nacional). De hecho ese disimulo posibilita paradójicamente la exposición de las planchas anatómicas que muestran descarnadamente el cuerpo humano, como seńala Santiago. Es justamente esa estética fuertemente atravesada por lo "global", lo que hace surgir lo "local". Sin embargo, lo local no adopta la pretensión de delinear cierto carácter nacional de la cultura, como sí ocurría en el siglo XIX, es decir, la delimitación de mitos de identificación colectiva y formas de construcción identitaria a nivel país; sino que, precisamente lo que surge en esa imagen "local", es la figura del despojo y de aquellos que políticamente están en las antípodas del proyecto nacional: los desarrapados. De modo que esa estrategia de ocultamiento en un molde cosmopolita, importador de formas, redunda en una visibilización de los márgenes sociales y la deconstrucción de la identidad chilena. Lo que saca a relucir es 
aquel borde incómodo para el proyecto político nacional, que en el contexto está ineludiblemente vinculado al gobierno militar.

En relación al entre-lugar para el escritor latinoamericano, la vocación explícita de intervenir en la discusión literaria se vislumbra en el apartado "Para la formulación de una imagen en literatura", donde - como mencionamos - se puede leer el gesto metapoético:

Entonces/ Los chilenos esperamos los mensajes/ L. Iluminada, toda ella/ Piensa en Lezama y se las frota/ Con James Joyce se las frota/ Con Neruda Pablo se las frota/ Con Juan Rulfo se las frota/ Con E. Pound se las frota/ Con Robbe Grillet se las frota/ Con cualquier fulano se frota las antenas (Eltit, p.69).

En este fragmento aparece por primera vez en el texto la mención a la cuestión de los chilenos como sujetos "nacionales" que se inscriben en determinada "comunidad imaginada", en términos de Benedict Anderson (1990), quien señala que el carácter nacional se funda, en algún punto, en una dimensión imaginada en tanto los ciudadanos de las sociedades modernas pierden los unos con los otros los lazos "directos" e inmediatos, a raíz de las mediaciones espaciales, las explosiones demográficas, etc. Esto hace que jamás se sepa el nombre ni se conozca al resto de los "compatriotas" sin que por ello dejen deincluirse dentro de ese entramado imaginado, donde no se abdica de la "confianza completa en su actividad sostenida, anónima, simultánea" (Anderson, 1990, p.57) y de la idea de que se constituye una "comunidad sólida que avanza sostenidamente de un lado hacia otro de la historia" (Anderson, 1990, p.57). De modo que no deja de 
ser significativa esta categoría en un texto en que las marcas de lo "local", o de lo específico nacional en gran medida son escatimadas. En ese sentido, la figura del sujeto nacional "los chilenos" es ubicada aquí en una posición de pasividad, a la espera de la recepción de un "mensaje” ¿político? ¿estético? Lo que en todo caso resulta interesante de la idea de "mensaje" es que utilizado en este contexto, más bien literario (lo que aparece a continuación es una seguidilla de nombres de literatos), tiene cierto tinte satírico. En sí pertenece a cierta(s) teoría(s) de la comunicación, con anclaje en Roman Jakobson, entre otros, que están pensando en un paradigma lingüístico que presupone un entendimiento recíproco entre un emisor y un receptor a partir del "mensaje" transmisible, igual a sí mismo, sin pérdidas ni deformaciones. Este paradigma aplicado a la esfera literaria no deja de resultar irónico en relación a la cuestión geopolítica de las literaturas mundiales, con sus regímenes de circulación, su jerarquización en "centros" y "periferias", etc. Ese carácter de recepción "pasiva" de "los chilenos" es desarticulada, a continuación, a partir de una actividad intensa - y erótica - de L. Iluminada, quien realiza el gesto desacralizador de "frotarse las antenas" ante los grandes faros literarios, tanto norteamericanos, latinoamericanos y europeos -incluso la literatura nacional, chilena. No sólo hace intervenir el carácter sexual - y en tanto tal, subversivo - que atraviesa todo el texto, en función de los "frotamientos" que no dejan de aparecer en él, las fricciones de las superficies en contacto, etc.; sino que además L. Iluminada está sujeta a una animalización, y en tanto que interviene objetos estéticos, puede también doblemente desacralizarlos a partir de un posible contagio de aquella animalidad. En ese sentido, aparece funcionando el concepto de "entre-lugar" en que el latinoamericano opera 
a partir de la posibilidad del desvío de la norma y entre "entre la sumisión al código y la agresión" (1978, p.76). La idea de una escritura sobre otra escritura, no sólo en términos bajtinianos (de que nadie quebraría el silencio del mundo por primera vez), sino también en el sentido de que ese corpus canónico es conocido, y se reconoce su presencia; aunque se subvierta su potencia modélica. Por otra parte, también resulta fundamental el gesto político: ubicar a L. Iluminada, una excluida social, como aquella que puede dar cuenta de dónde estaría la potencia del latinoamericano para intervenir en los debates estéticos.

Para concluir, en Lumpérica lo local y lo global se encuentra tensionado tanto en el plano temático (y político) como también en el teórico-estético, a partir de las elecciones implícitas y las afirmaciones metapoéticas que se realizan de forma explícita. Observamos que el corrimiento de lo local general: "Chile", hacia lo local específico: los lúmpenes, configura una operación de política signada a partir de los límites de aquello que se puede decir en un contexto dictatorial. Estos adoptan, de forma momentánea, el carácter de "chilenos" a partir del elemento global publicitario (el cartel). Ahora bien, en relación a la idea expuesta por Eva Klein respecto a que los desposeídos, a pesar de vivir en Chile, "no parecen tener lazos de pertenencia imaginaria, ni simbólica, con ninguna comunidad nacional" (2002, p.22), nos parece que, por el contrario, el texto se encarga de ubicar a los desarrapados en aquel espacio (vacante) que da cuenta de la identidad nacional: los ubica en lugar de "los chilenos". Y por el otro lado, la elección por corrientes estéticas y teóricas postestructuralistas permiten no sólo un ocultamiento o disimulo del aspecto contextual, sino también una apropiación estética, a partir de 
ese entre-lugar latinoamericano. De esta manera, aquellas teorías extranjeras se subvierten, se desvían y dado que están sujetas a otros usos, se vuelven "locales".

\section{REFERENCIAS BBLLIOGRÁFICAS}

Adam, Jean-Michel; Heidemann, Ute. "Des genres à la généricité. L’exemple des contes (Perrault et les Grimm)”. En Langages, 38e année, no 153, 2004, 52-72.

Anderson, Benedict. Imagined Communities. Reflections on the Origin and Spread of Nationalism. London, New York: Verso, 1990.

Barrientos, Mónica. "Cartografías quebradas y cuerpos marginales en la narrativa de Diamela Eltit" en Debate feminista, 53, 2017, 18-32.

Barrientos, Mónica. "La construcción estéticadelaimagen enlaperformanceZonas de dolor de Diamela Eltit". AISTHESIS, 61, 2017, 145-166.

Bortignon, Martina. "Lumpérica de Diamela Eltit, o el arte de la ambivalencia como potencial ético y estético en el contexto de la biopolítica neoliberal". Confluenze, v 3, 2, 2011.

Eltit, Diamela. Lumpérica. Santiago de Chile: Ediciones del Ornitorrinco, 1983.

Klein, Eva. "La (auto)representación en ruinas: Lumpérica de Diamela Eltit". En Iberoamericana, II, 7, 2002, 19-28.

Martín, Alberto. "Espacio, movimiento y afecto en Lumpérica y Vaca sagrada, de Diamela Eltit" en Dissidences. Hispanic Jounal of Theory and Criticism. v 7, 12, 2016, 1-26.

Paniagua García, José Antonio. "La frontera y la herida: Lumpérica de Diamela Eltit” en Anales de Literatura Hispanoamericana, vol. 43, Núm. Especial, 2014, 71-83. 
Reber, Dierdre. "Lumpérica: el ars teórica de Diamela Eltit" en Revista Iberoamericana, Vol. 71, 211, 2005, 449-470.

Santiago, Silviano. Uma literaturanos trópicos: ensaios sobre dependencia cultural. Sao Paulo: Editorial Perspectiva, 1978.

Schwarz, Roberto. "Brazilian Culture: Nationalism by elimination" En New Left Review, 167 (Jan.-Feb.), 1988.

Schwarz, Roberto. "Las ideas fuera de lugar". En Amante, Adriana y Florencia Garramuño. Absurdo Brasil. Buenos Aires: Biblos, 2000.

Solorza, Paola. "Entrevista a Diamela Eltit: una literatura no consensual: cuerpo, lugares border y resistencia”. En Anclajes, Vol. 20, No. 1, 2016. 